\begin{tabular}{|c|c|c|c|}
\hline \multirow{3}{*}{$\begin{array}{r}\text { Case Reports in } \\
\text { Gastroenterology }\end{array}$} & \multirow{2}{*}{\multicolumn{2}{|c|}{ Case Rep Gastroenterol 2018;12:137-142 }} & \multirow[b]{3}{*}{$\begin{array}{l}\text { Karger } \\
\text { Open access }\end{array}$} \\
\hline & & & \\
\hline & $\begin{array}{l}\text { DOI: 10.1159/000488195 } \\
\text { Published online: April 13, } 2018\end{array}$ & $\begin{array}{l}\text { ( } 2018 \text { The Author(s) } \\
\text { Published by S. Karger AG, Basel } \\
\text { www.karger.com/crg }\end{array}$ & \\
\hline & $\begin{array}{l}\text { This article is licensed under } t \\
\text { International License (CC BY-N } \\
\text { Usage and distribution for comm }\end{array}$ & $\begin{array}{l}\text { nons Attribution-NonCommercial } 4.0 \\
\text { ger.com/Services/OpenAccessLicense). } \\
\text { uires written permission. }\end{array}$ & \\
\hline
\end{tabular}

\title{
Exclusive Phlebosclerosis of Submucosal Veins Leading to Ischemic Necrosis and Perforation of the Large Bowel: First European Case
}

\author{
Sebastian Klein ${ }^{a}$ Denise Buchner ${ }^{b}$ De-hua Chang ${ }^{c}$ Reinhard Büttner ${ }^{a}$ \\ Uta Drebber $^{\mathrm{a}}$ Jochen W.U. Fries ${ }^{\mathrm{a}}$ \\ anstitute for Pathology, University Hospital Cologne, Cologne, Germany; \\ bDepartment of Surgery, University Hospital Cologne, Cologne, Germany; \\ 'Department of Radiology, University Hospital Cologne, Cologne, Germany
}

\section{Keywords}

Phlebosclerotic colitis · Submucosal veins · Left-sided colon

\begin{abstract}
Phlebosclerotic colitis (PC) is a rare, potentially life-threatening disease of unclear pathogenesis almost exclusively reported in Asian patients of both genders. A fibrous degeneration of venous walls leads to threadlike calcifications along mesenteric vessels and colonic wall thickening, detectable by CT. This causes disturbed blood drainage and hemorrhagic infarction of the right-sided colonic wall. This is a report of PC in a Caucasian woman in Europe without Asian background and no history of herbal medications, a suspected cause in Asian patients. CT revealed no calcification of the mesenteric vein or its tributaries. Instead, submucosal veins of the left-sided colonic wall were calcified, leading to subsequent transmural necrosis. Clinically, the patient developed a paralytic ileus and sigmoidal perforation during a 2-week hospitalization due to a bleeding cerebral vascular aneurysm. This case of a European woman with PC is unique in its course as well as its radiologic, clinical, and pathologic presentation.




\section{Case Reports in Gastroenterology}

Case Rep Gastroenterol 2018;12:137-142 DOI: 10.1159/000488195

(c) 2018 The Author(s). Published by S. Karger AG, Basel www.karger.com/crg

Klein et al.: Exclusive Phlebosclerosis of Submucosal Veins Leading to Ischemic Necrosis and Perforation of the Large Bowel: First European Case

\section{Introduction}

Phlebosclerotic colitis (PC) is a rare disease where a chronic ischemia of the large intestinal bowel with calcification of the mesenteric venous system is causing colonic congestion and even hemorrhagic infarction [1]. While the underlying pathophysiology remains uncertain, a few reports have highlighted that certain toxins, portal hypertension, diabetes mellitus, dyslipidemia, or hemodialysis are associated with the disease [2, 3]. Ischemic intestinal bowel diseases that are linked to a disturbed blood flow are most commonly found in the left colon, especially in patients with risk factors including smoking, hypertension, arteriosclerosis, and diabetes mellitus [4]. However, PC almost exclusively affects the right colon, underlining the hypothesis that certain toxins could play a role in the pathogenesis of the disease [5]. Here, we report a unique case of a Caucasian female patient with a left-sided PC and without history of herbal medicine intake. Her symptoms developed during a 2-week hospitalization for a bleeding cerebral aneurysm due to a sigmoidal perforation. This case is unique in its epidemiologic, radiologic, clinical, and pathologic presentation.

\section{Case Report}

A 63-year-old female Caucasian patient was admitted to the hospital with nausea and vomiting. The patient presented in an acutely ill state and was transferred to the intensive care unit, where an intraventricular cranial bleeding was detected and drained. Throughout the next 7 days of treatment, the abdomen was distended and tympanic, and bowel sounds were decreased. A CT scan showed a paralytic ileus with increased thickness of the colonic wall but without signs of threadlike calcification of the mesenteric vein or its tributaries (Fig. 1). Further evaluation by endoscopy revealed an ischemic colitis of the left-sided colon, developing subsequent signs of peritonitis. A sigmoidal perforation was detected and an extended left-sided colectomy performed due to the intraoperative finding of a long-stretched ulcerative colitis progressing from the transverse to the distal sigmoid colon. Upon gross examination, a thickened colonic wall, together with a necrotic mucosal epithelium and mural calcifications, suggested a vascular-mediated disease (Fig. 2a, inset). Histologically, the colonic wall showed extensive calcifications of the submucosal layer with long-stretched mucosal ulcerations (Fig. 2a). Interestingly, only submucosal veins showed a subtotal occlusive fibrosis, sclerosis, and calcification (Fig. 2b). Arterial vessels or veins of the mesentery or of the epiploic appendices were not affected. The calcification was confirmed by von Kossa stain (Fig. 2c), leading to the rare diagnosis of PC.

\section{Discussion}

The presented case has unique features in comparison to the already published 33 case reports in the literature. The vast majority of patients are of Asian descend of both sexes, ranging in age from their forties to their early seventies; only in two cases, the disease is described in younger patients of 35 years of age [6,7]. Besides a single report from North America, this is the first case seen in Europe from a woman neither of Asian descent nor having lived in Asia [8]. Typically, this disease is described in the right-sided colon, occasionally extending into the Bauhin's valve and the terminal ileum [8]. Additional cases were described where lesions extend into the transverse colon [9]. In exceptional cases, the entire 


\section{Case Reports in Gastroenterology}

Case Rep Gastroenterol 2018;12:137-142

DOI: $10.1159 / 000488195$

(c) 2018 The Author(s). Published by S. Karger AG, Basel www.karger.com/crg

Klein et al.: Exclusive Phlebosclerosis of Submucosal Veins Leading to Ischemic Necrosis and Perforation of the Large Bowel: First European Case

intestine may be involved [10]. In our case, the disease started from the mid-transverse to the distal sigmoid colon, thus being most prominent in the left colon and leaving the rightsided colon uninvolved. CT scans are thought to be rather specific in diagnosing PC with findings including calcification of the mesenteric veins and its tributaries. A semiquantitative scoring system of calcifications was described, using their distribution along the straight, marginal, and main branch of mesenteric veins [11]. While angiographic evaluation primarily focuses on arterial blood flow, PC patients may present with a decreased venous phase perfusion that might be difficult to quantify. However, this leads to an obstructive blood flow and underperfusion of the affected vascular region of the bowel. In our case, however, no calcifications - as considered typical for PC - could be detected by CT (Fig. 1). Although there is no specific clinical presentation of patients with these radiologic signs suffering from PC, histological hallmarks of the disease include venous fibrosis, sclerosis, calcification, and hyalinization, together with colonic wall thickening. The calcifications of the mesenteric veins led to the name of phlebosclerotic colitis [1]. While the vascular lesions in our case basically showed similar morphologic features (Fig. 2a), the major difference was the affected vascular region. Instead of being observed primarily in the larger veins of the mesentery, in our case we exclusively observed the involvement of submucosal veins (Fig. 2b, c), while the arteries were histologically normal. As was noted already in the early reports, calcifications of the larger veins can be deleterious, leading to reduced drainage with secondary ischemic damage $[2,12]$. Consequently, the extensive involvement of all submucosal veins investigated with luminal narrowing in our case is even more catastrophic, since the congested blood flow and reduced oxygenation take immediate effect on the most vulnerable part of the colonic wall, its mucosa. This explains the extensive mucosal necrosis mimicking ulcerative colitis, which was the suspected clinical diagnosis in our case. Thus, clinical symptoms vary depending on the degree and extent of vascular involvement, in particular the degree of calcification [11]. Frequently, diarrhea with or without bleeding, abdominal pain, abdominal distension, or even constipation as well as intestinal obstruction have been described [3]. In milder forms, no surgery has been required. However, rarely a bowel perforation occurred, needing surgical resection as is the case in more extensive colonic necrosis [12]. Hence, our case is unique as it combines a usual involvement of the distal colon with the most feared complication of a perforation clinically presenting itself as a peritonitis. Pathogenetically, in our case there are no known toxins as well as no clinical signs of portal hypertension, diabetes mellitus, or dyslipidemia. Our patient had a normally functioning kidney and no signs of portal hypertension. Further risk factors for typical ischemic intestinal bowel diseases linked to a disturbed blood flow, such as smoking, hypertension, arteriosclerosis, and diabetes mellitus, were clinically not present [4]. Another striking difference to the currently reported cases is the time frame of events. Reported cases show a rather prolonged and insidious course with slow progression [12], while the beginning of the disease process in our patient remains unknown, due to lacking symptoms and without prior hospitalization within the last 7 years, according to his primary care physician. This case had an as yet undescribed accelerated and dramatic progression within 2 weeks of hospitalization. Regarding the observation that hemodialysis can be a contributing factor for the development of PC with its calcifications of the smooth muscle-containing venous vessel wall, it is interesting to compare the similarities of this vascular lesion to the arterial media calcification [2]. Dialysis seems to be a potentially major mediator, which in both diseases causes a circumferential calcification of smooth muscle cells with preservation of the endothelial cell layer. Pathogenetically, there is a degenerative and not an inflammatory process leading to reduced perfusion and hypoxia-related tissue necrosis. 
Klein et al.: Exclusive Phlebosclerosis of Submucosal Veins Leading to Ischemic Necrosis and Perforation of the Large Bowel: First European Case

\section{Conclusion}

The presented case of PC is unique in its epidemiologic, radiologic, clinical, and pathologic presentation. Regarding potential complications such as bowel perforation, in cases of ischemic ulcerative colitis, an unusual pathogenesis should be considered and ruled out to prevent a sudden, life-threatening progress. The clinical evaluation, however, is complicated, since in the majority of cases, no causative chain of events in PC has clearly been identified. Thus, applying our current knowledge to unusual presentation of colitis and sharpening our clinical awareness of this disease by publishing additional cases will allow us to collect further insights into this disease, enabling us to ultimately solve the PC puzzle.

\section{Statement of Ethics}

Patient consent was obtained.

\section{Disclosure Statement}

The authors declare that they have no competing interest.

\section{References}

1 Iwashita A, Yao T, Schlemper RJ, Kuwano Y, Yao T, Iida M et al. Mesenteric phlebosclerosis: a new disease entity causing ischemic colitis. Dis Colon Rectum. 2003 Feb;46(2):209-20.

2 Song JH, Kim JI, Jung JH, Kim JH, Lee SH, Cheung DY et al. [A case of phlebosclerotic colitis in a hemodialysis patient]. Korean J Gastroenterol. 2012 Jan;59(1):40-3.

3 Lee SH et al. Obstructive ileus caused by phlebosclerotic colitis. Intest Res. 2016 Oct;14(4):369-74.

4 Gandhi SK, Hanson MM, Vernava AM, Kaminski DL, Longo WE. Ischemic colitis. Dis Colon Rectum. 1996 Jan;39(1):88-100.

5 Chang KM. New histologic findings in idiopathic mesenteric phlebosclerosis: clues to its pathogenesis and etiology—probably ingested toxic agent-related. J Chin Med Assoc. 2007 Jun;70(6):227-35.

6 Yen TS, Liu CA, Chiu NC, Chiou YY, Chou YH, Chang CY. Relationship between severity of venous calcifications and symptoms of phlebosclerotic colitis. World J Gastroenterol. 2015 Jul;21(26):8148-55.

7 Park JK, Sung YH, Cho SY, Oh CY, An SH. Phlebosclerotic colitis in a healthy young woman. Clin Endosc. 2015 Sep;48(5):447-51.

8 Markos V, Kelly S, Yee WC, Davis JE, Cheifetz RE, Alsheikh A. Phlebosclerotic colitis: imaging findings of a rare entity. AJR Am J Roentgenol. 2005 May;184(5):1584-6.

$9 \quad \mathrm{Hu}$ P, Deng L. Phlebosclerotic colitis: three cases and literature review. Abdom Imaging. 2013 Dec;38(6):1220-4.

10 Chen MT, Yu SL, Yang TH. A case of phlebosclerotic colitis with involvement of the entire colon. Chang Gung Med J. 2010 Sep-Oct;33(5):581-5.

11 Yen TS, Liu CA, Chiu NC, Chiou YY, Chou YH, Chang CY. Relationship between severity of venous calcifications and symptoms of phlebosclerotic colitis. World J Gastroenterol. 2015 Jul;21(26):8148-55.

12 Fang YL, Hsu HC, Chou YH, Wu CC, Chou YY. Phlebosclerotic colitis: A case report and review of the literature. Exp Ther Med. 2014 Mar;7(3):583-6. 


\section{Case Reports in Gastroenterology

\begin{tabular}{l|l}
\hline Case Rep Gastroenterol 2018;12:137-142 \\
\hline DOI: 10.1159/000488195 & $\begin{array}{l}\text { @ 2018 The Author(s). Published by S. Karger AG, Basel } \\
\text { www.karger.com/crg }\end{array}$ \\
\hline
\end{tabular} \\ Klein et al.: Exclusive Phlebosclerosis of Submucosal Veins Leading to Ischemic Necrosis and Perforation of the Large Bowel: First European Case}

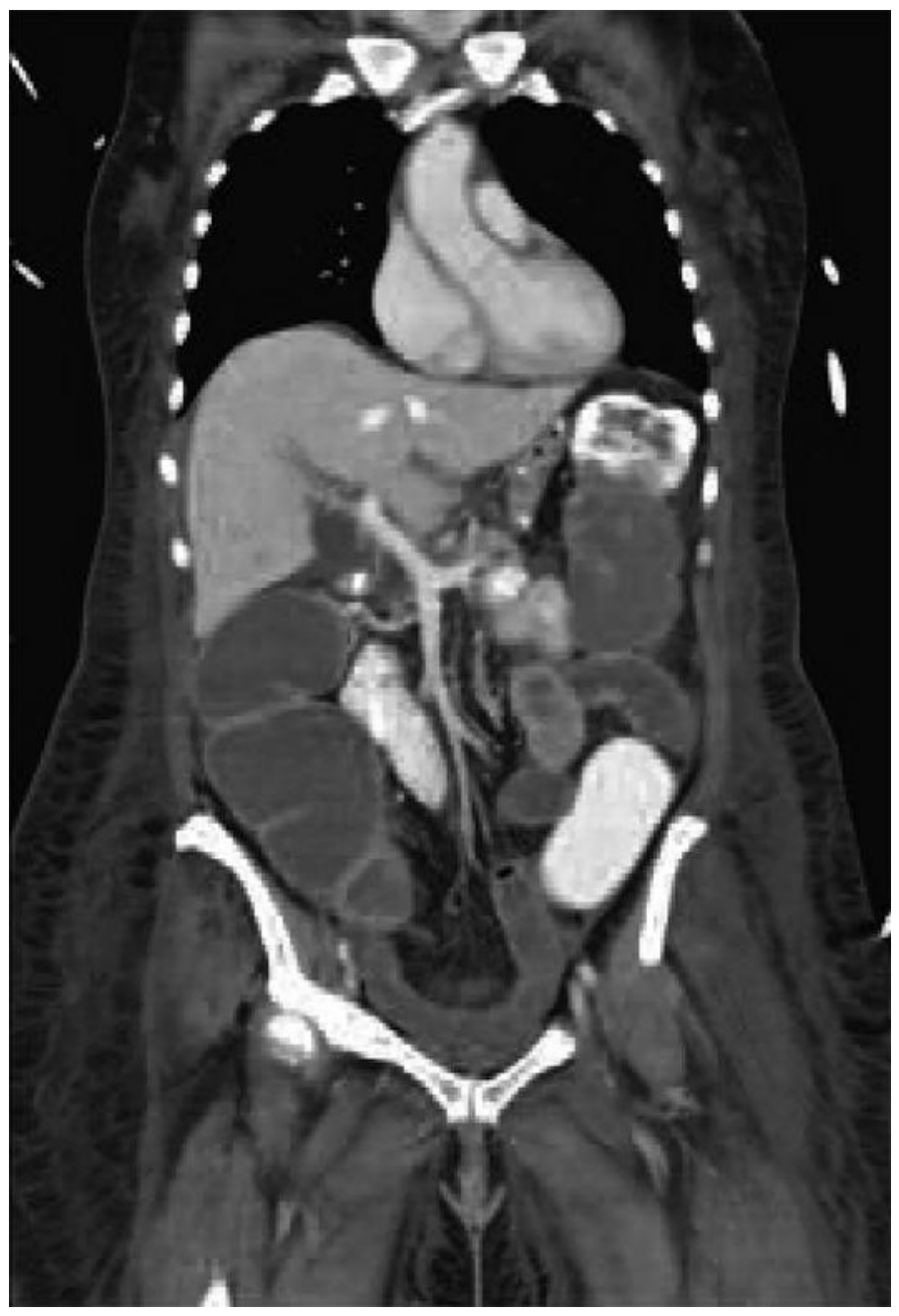

Fig. 1. CT scan of abdomen without visible calcification of the mesenteric vein and its contributories. Colonic wall thickened. 


\section{Case Reports in \\ Gastroenterology}

\begin{tabular}{l|l}
\hline Case Rep Gastroenterol 2018;12:137-142 \\
\hline DOI: 10.1159/000488195 & $\begin{array}{l}\text { ○ 2018 The Author(s). Published by S. Karger AG, Basel } \\
\text { www.karger.com/crg }\end{array}$ \\
\hline
\end{tabular}

Klein et al.: Exclusive Phlebosclerosis of Submucosal Veins Leading to Ischemic Necrosis and Perforation of the Large Bowel: First European Case

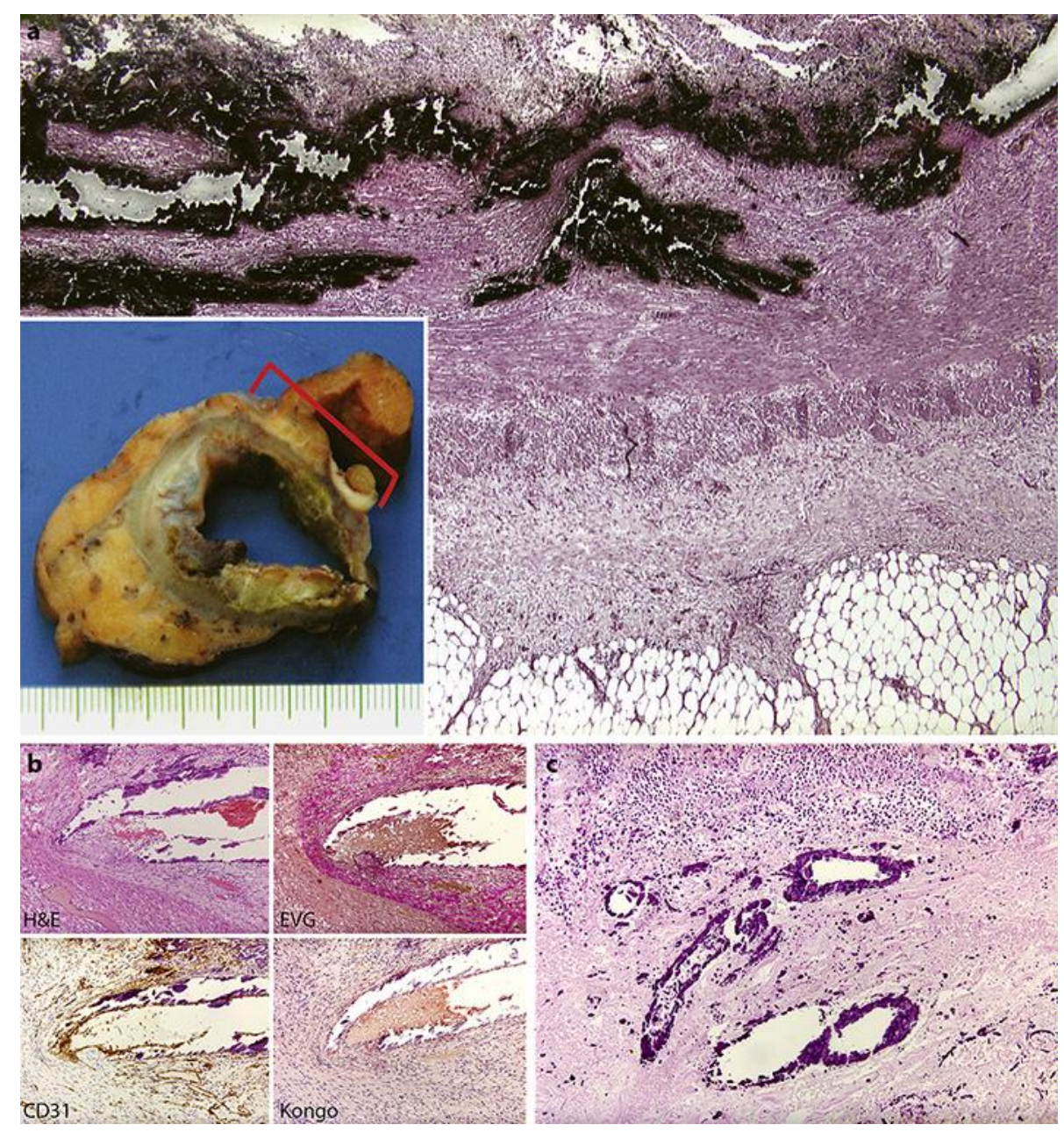

Fig. 2. Macroscopic and microscopic pictures of the left-sided colonic wall. a Extensive necrosis of mucosa and submucosa. Red bracket marks area of histology, with von Kossa staining showing extensive calcification of the submucosal area. Original magnification 25×. b Details of venous wall with H\&E, CD31, EVG, and Kongo-red staining showing submucosal calcification with luminal narrowing. Immune histology reveals preserved endothelial layer with submucosal calcification without inflammation. c Calcification of the submucosal veins. H\&E staining. Original magnification 100×. 